\title{
Erratum to: Increased risk of hip fractures in Korean patients with type 2 diabetes: a 6-year nationwide population-based study
}

\author{
Se Hwa Kim ${ }^{1,2} \cdot$ Yoo Mee Kim ${ }^{1,3} \cdot$ Jeong Seon Yoo $^{1} \cdot$ Eun Yeong Choe $^{1} \cdot$ \\ Tae Ho Kim ${ }^{4}$ Young Jun Won ${ }^{1,2}$
}

Published online: 27 January 2017

(C) The Japanese Society for Bone and Mineral Research and Springer Japan 2017

\section{Erratum to: J Bone Miner Metab \\ DOI 10.1007/s00774-016-0798-z}

In the original publication of the article, the following description was not included in the Acknowledgments section. The statement is given below:

"This study used NHIS-NSC data (NHIS-2014-2-044) made by National Health Insurance Service (NHIS). The authors declare no conflict of interest with NHIS".

The online version of the original article can be found under doi:10.1007/s00774-016-0798-z.

Young Jun Won

yjwon@ish.ac.kr; yjwon00@gmail.com

1 Division of Endocrinology and Metabolism, Department of Internal Medicine, Catholic Kwandong University College of Medicine, International St. Mary's Hospital, Simgokro 100gil 25, Seo-gu, Incheon Metropolitan City 404-834, South Korea

2 Institute for Bio-Medical Convergence, Catholic Kwandong University College of Medicine, International St. Mary's Hospital, Incheon, South Korea

3 Institute for Translational and Clinical Research, Catholic Kwandong University College of Medicine, International St. Mary's Hospital, Incheon, South Korea

4 Division of Endocrinology, Department of Internal Medicine, Seoul Medical Center, Seoul, South Korea 